\title{
Assessing the relationship between infantile colic and parental migraine in infants aged 4 to 12 weeks in Urmia
}

\author{
Ezatolah Abbasi $^{\circledR}$, Ahad Ghazavi $^{2^{*}}{ }^{\circledR}$, Kamran Dehghan $^{3}{ }^{\circledR}$, Mahsa Soleimani $^{4}$ \\ ${ }^{1}$ Department of Pediatric Neurology, Urmia University of Medical Sciences, Urmia, Iran \\ ${ }^{2}$ Neurophysiology research center, Urmia University of Medical Sciences, Urmia, Iran \\ ${ }^{3}$ Department of Pediatric Disease, Urmia University of Medical Sciences, Urmia, Iran \\ ${ }^{4}$ Urmia University of Medical Sciences, Urmia, Iran
}

Correspondence to:

Ahad Ghazavi, Email:

ghazavi.a@umsu.ac.ir

Received: 19 April 2020 Accepted: 18 June 2020 ePublished: 9 December 2020

Keywords: Infantile colic, Infants, Parental migraine

\begin{abstract}
Introduction: Infantile colic affects $5 \%$ to $19 \%$ of infants.

Objectives: This study aimed to investigate the relationship between infantile colic crying and migraine in parents.

Patients and Methods: In this study, the infants referred to Urmia health centers with 4 to 12 weeks old were investigated. According to the definition of infantile colic and questioning the parents, those infants were identified who cried at least three hours a day, at least three days a week, for at least 3 weeks. By filling out a questionnaire on infantile colic and migraine in parents, the relationship between migraine in parents and colic in infants was examined.

Results: In this study, 195 infants aged 4 to 12 weeks were included. Around 107 (54.9\%) were male. The mean age of infants was $6.50 \pm 2.10$ weeks. Of the 195 infants, $65(33.3 \%)$ had colic, $32(49.2 \%)$ were male and $33(50.8 \%)$ were female $(P=0.26)$. Around $47(24.1 \%)$ of parents had migraine and $148(75.9 \%)$ had no history of migraine. Of 65 infants with colic, $38(58.5 \%)$ had migraine parents and 27 (41.5\%) had no history of parental migraine. Of 130 infants without colic, $9(6.9 \%)$ of the parents had a history of migraine and 121 (93.1\%) of them had no migraine ( $P=0.001)$. Of 65 infants with colic, 31 of the mothers had migraine, since of 130 infants without colic, none of their mothers complained about migraine $(P=0.001)$.

Conclusion: Infantile colic was significantly associated with parental migraine and it could be an early sign of disease in infants.
\end{abstract}

\section{Introduction}

Citation: Abbasi E Ghazavi A, Dehghan K, Soleimani M. Assessing the relationship between infantile colic and parental migraine in infants aged 4 to 12 weeks in Urmia. J Prev Epidemiol. 2020;5(2):e22 doi: $10.34172 /$ jpe.2020.22
Infantile colic in infants with no health problems affects 5 to 19 percent of infants $(1,2)$. However, this ratio is also mentioned in some articles to include up to $40 \%$ (35). Infantile colic is a prolonged crying. Naturally, crying in the infant increases in the first weeks of life, reaches a peak around the fifth and sixth weeks of life, and then gradually ends by three months $(6,7)$. The most accepted definition of infantile colic in the scientific community is "Rule 3": crying for at least three hours a day, at least three days a week, and for at least three consecutive weeks. The first two components of this definition are derived from the studies of Wessel et al (8); but the third component is often controversial because of the difficulty in documenting the data. Other definitions for infantile colic include severe crying for several hours per day (9) and crying for more than two (10) or three (11) hours per day. In studies that do not define the duration of an

\section{Key point}

In a study on 195 infants aged 4 to 12 weeks, we found infantile colic was significantly associated with parental migraine and it could be an early sign of disease in infants.

infant's cry, infantile colic is described as an unjustified cry (12), a cry that has become a problem (13), and a cry that parents cannot tolerate and need help to control it (14). Regardless of these differences, all studies agreed that these infants are healthy, have no growth problems, and are all under 6 months of age (1).

Infantile colic crying is highly distressing for parents or caregivers and is associated with the caregiver's desperation (15) and shaken baby syndrome $(16,17)$. Causes such as sensitivity to cow's milk proteins, intestinal absorption disorders, parentalrelated factors, and central nervous system disorders have been some causes of pain

Copyright (C) 2020 The Author(s); Published by Society of Diabetic Nephropathy Prevention. This is an open-access article distributed under the terms of the Creative Commons Attribution License (http://creativecommons.org/licenses/by/4.0), which permits unrestricted use, distribution, and reproduction in any medium, provided the original work is properly cited. 
leading to colic crying (18).

While the word colic may lead the reader to the problems of digestive origin, no definitive evidence has yet been found to indicate a direct cause in the gastrointestinal system that could lead to crying in the infant (19). Despite extensive researches in this area, our knowledge of the cause of these cries has not changed significantly from what we learned from the researches of Wessel in 1954 (8). Some studies have suggested that childhood periodic syndromes, such as benign attack vertigo syndrome or benign attack torticollis syndrome, may be the primary manifestations of the genes that later cause migraine (20).

In this regard, there is also information that suggests that infantile colic cries can be also an early manifestation of migraine disease $(21,22)$. How migraine in genetics causes colic is unclear, but it has been suggested that an increased sensitivity to the stimuli such as sound, light, cold air and the movement that occurs during migraine attacks, may be the cause of these cries $(23,24)$. In another study, parents improved their infantile colic crying by controlling and reducing environmental stimuli (14).

\section{Objectives}

Given the high prevalence of migraine in women, especially Caucasian women, the bad impact of colic crying on family and infant health, and the probable relationship between parental migraine and colic crying in their offspring, this study was conducted to investigate the relationship between colic crying in infants and migraine in parents.

\section{Patients and Methods}

\section{Study design}

The current study was a descriptive cross-sectional conducted on the infants aged 4 to 12 weeks old who were referred to Urmia health centers. Regarding the definition of colic and questioning the parents, those infants were identified who were crying at least three hours a day, at least three days a week for at least three weeks; then filling out a questionnaire about infantile colic and migraine in parents, the relationship between migraine in parents and colic in infants was investigated. Exclusion criteria were the existence of any disease or disorder, such as infection or urinary tract stones and gastro-esophageal reflux, which lead to crying and restlessness of the child. According to the corresponding formula for estimating the two proportions with $95 \%$ confidence and $90 \%$ power and using the results of the study of Gelfand et al (P2 =0.10, P1 = 0.22) (25), the total sample size was 195 individuals. They were selected at convenience from among the parents with children aged 4 to 12 weeks, who referred to the selected urban health centers of Urmia.

\section{Ethical issues}

Human rights were respected in accordance with the Helsinki Declaration 1975, as revised in 1983. The informed consent was taken from the patients. The study was approved by ethics committee of Urmia University of Medical Science (Ethical cod\# IR.UMSU.REC.1398.056). This study was taken from the medical thesis done by Mahsa Soleimani (\#3285).

\section{Statistical analysis}

To describe the quantitative data, the central and dispersion indices (mean and standard deviation) were calculated and the qualitative variables were reported in frequency and percentage; appropriate tables and diagrams were used as needed. Appropriate statistical tests were used for comparison in terms of data distribution and normality like chi-square. All analyzes were performed using SPSS, version 21, software and the level of significance was lower than 0.05 in all statistical tests $(P<0.05)$.

\section{Results}

In this study, 195 infants aged 4 to 12 weeks were included in the study. Around 107 infants (54.9\%) were male and $88(45.1 \%)$ were female. The mean age of infants was $6.50 \pm 2.10$ weeks. The mean age of the female infants was $6.621 .99 \pm$ weeks and in the male infants was $6.40 \pm 2.20$ weeks. According to the t-test, there was no significant difference between the age of infants $(P=0.46)$. Of 195 infants, 65 (33.3\%) had colic. About 47 (24.1\%) of parents had migraine and 148 (75.9\%) had no history of migraine (Table 1). Of 65 infants with colic, 38 parents (58.5\%) had migraine and $27(41.5 \%)$ of them had no migraine. Of 130 infants without colic, 9 parents $(6.9 \%)$ had a history of migraine and 121 (93.1\%) were without the history of migraine. According to chi-square test, a significant difference between the history of parental migraine and infantile colic was detected $(P=0.001)$. Of 65 infants with colic, 32 (49.2\%) were male and 33 (50.8\%) were female. Of 130 infants who did not have colic, 75 (57.7\%) were male and 55 (42.3\%) were female. According to chi-square test, no significant relationship between colic and infantile gender was seen $(P=0.26$; Table 2$)$.

Of the 65 infants with colic, 37 (56.9\%) were in the age group of 4-6 weeks, 15 (23.1\%) in the age group of 6-8 weeks, $10(15.4 \%)$ in the age group of 8-10 weeks and three infants $(4.6 \%)$ were in the age group of $10-12$ weeks. Of the 130 infants who did not have colic, 46 (35.4\%) were in

Table 1. Demographic characteristics of the infants under study

\begin{tabular}{lcc}
\hline Variable & Absolute frequency & Relative frequency \\
\hline Male & 107 & 54.9 \\
Female & 88 & 45.1 \\
Total mean age (week) & $6.50 \pm 10.2$ & \\
Male mean age & $6.62 \pm 1.99$ & $P=0.46$ \\
Female mean age & $6.40 \pm 2.20$ & \\
With colic & 65 & 33.3 \\
Without colic & 130 & 66.7 \\
History of migraine in & 47 & 24.1 \\
parent, Yes/No & 148 & 75.9 \\
\hline
\end{tabular}


Table 2. Determining the relationship between infantile colic and migraine in parents

\begin{tabular}{|c|c|c|c|}
\hline \multirow{2}{*}{ Infantile colic } & \multicolumn{2}{|c|}{ History of migraine in parent } & \multirow{2}{*}{ Total } \\
\hline & Yes & No & \\
\hline Yes & $38(58.5 \%)$ & $27(51.4 \%)$ & $65(100 \%)$ \\
\hline No & $9(6.9 \%)$ & $121(93.1 \%)$ & $130(100 \%)$ \\
\hline
\end{tabular}

the age group of 4-6 weeks, 41 (31.5\%) in the age group of 6-8 weeks, $30(23.1 \%)$ in the age group of $8-10$ weeks and three infants (10\%) were in the age group of $10-12$ weeks. Chi-square test showed a significant relationship between infantile colic and infant age group $(P=0.03$; Table 3$)$.

Of 65 infants with colic, 31 mothers of these infants had migraine, and of 130 infants without colic, none of their mothers complained of migraine. According to chi-square test, there was a significant relationship between maternal migraine and infantile colic $(P=0.001$; Table 4$)$.

Of 65 infants with colic, seven of their fathers had migraine and six of the fathers of 130 infants (4.6\%) had migraine. Chi-square test showed no significant relationships between father's migraine and infantile colic $(P=0.10$; Table 5).

\section{Discussion}

Studies have provided a variety of definitions of infantile colic, all of which have a common characteristic of prolonged cry. The crying of infants naturally increases in the first weeks of life, reaches its peak around the fifth and sixth weeks of life, and then gradually ceases until three months of life $(6,7)$. The most accepted definition of infantile colic in the scientific community is "Rule 3": crying for at least three hours a day, at least three days a week, and for at least three consecutive weeks. The first two components of this definition have been derived from the studies of Wessel et al (8). Several studies have suggested migraine headaches as the cause of these cries. Thus, the aim of this study was to investigate the relationship between infantile colic and migraine in parents of infants aged 4 to 12 weeks with 195 infants, of whom 107 (54.9\%) were male and $88(45.1 \%)$ were female. In our study $65(33.3 \%)$ of the infants had colic while $32(49.2 \%)$ were male and 33 (50.8\%) were female. Although in this study no significant difference between the gender of infants and colic was detected, female infants had the highest percentage of colic $(P=0.26)$. In a study conducted by Gelfand et al, 22 infants (14\%) had colic and there were no significant differences in gender between colic patients. Nevertheless, 55\% of
Table 4. Frequency distribution of infantile colic based on migraine history in the mother

\begin{tabular}{|c|c|c|c|}
\hline \multirow{2}{*}{ Infantile colic } & \multicolumn{2}{|c|}{ History of migraine in mother } & \multirow{2}{*}{ Total } \\
\hline & Yes & No & \\
\hline Yes & $31(47.7 \%)$ & $34(52.3 \%)$ & $65(100 \%)$ \\
\hline No & $0(0 \%)$ & $130(100 \%)$ & $130(100 \%)$ \\
\hline Total & $31(15.9 \%)$ & $164(84.1 \%)$ & 195 (100\%) \\
\hline
\end{tabular}

Table 5. Frequency distribution of infantile colic based on migraine history in the father

\begin{tabular}{|c|c|c|c|}
\hline \multirow{2}{*}{ Infantile colic } & \multicolumn{2}{|c|}{ History of migraine in father } & \multirow{2}{*}{ Total } \\
\hline & Yes & No & \\
\hline Yes & $58(89.2 \%)$ & $7(10.8 \%)$ & $65(100 \%)$ \\
\hline No & $124(95.4 \%)$ & $6(4.6 \%)$ & $130(100 \%)$ \\
\hline Total & $182(93.3 \%)$ & $13(6.7 \%)$ & $195(100 \%)$ \\
\hline
\end{tabular}

female infants had colic; these results were consistent with the findings of our study in terms of infant gender, but contradicted it in terms of the percentage of infants with colic. In terms of percentage of infants with colic, $18 \%$ of mothers had migraine. The likelihood of colic in infants who had a positive history of migraine in their mothers was 2.6 times compared to the mothers who did not have migraine (29\% versus $11 \%$; prevalence ratio 2.6; CI: - 1.5 5.5, $P=0.02)(25)$.

In a study conducted by Tabrizi et al, a case-control study on the 5-15 year-old children, the relationship between infantile colic and childhood migraine had been examined. Ninety cases (54.88\%) were female (26). This was in line with the results of the current study in infants with colic in terms of gender. In this study, 17 (41.46\%) children with migraine headaches had a positive history for infant colic compared to the control group $(44,35.7 \%)$. The history of migraine was higher in the parents of children with colic than in children who did not have colic $(P=0.001)$, which was consistent with the results of the current study. In a study carried out by Ali et al, the incidence rate of infantile colic was $37 \%$, which was relatively consistent with the results of the current study. In their study, 47 parents (24.1\%) had migraine, and a significant relationship between infantile colic and migraine in parents was seen $(P<0.05)$. In their study, the infantile colic was evaluated based on the migraine in parents and the results showed a significant relationship between colic and maternal

Table 3. Determination of infantile colic frequency by the infant age

\begin{tabular}{lcccc}
\hline \multirow{2}{*}{ Infantile colic } & \multicolumn{3}{c}{ Age group } \\
\cline { 2 - 4 } & $\mathbf{4 - 6}$ & $\mathbf{6 - 8}$ & $\mathbf{8 - 1 0}$ & $\mathbf{1 0 - 1 2}$ \\
\hline Yes & $37(56.9 \%)$ & $15(23.1 \%)$ & $10(15.4 \%)$ & $3(4.6 \%)$ \\
No & $46(35.4 \%)$ & $41(31.5 \%)$ & $30(23.1 \%)$ & $13(10 \%)$ \\
Total & $83(42.6 \%)$ & $56(28.7 \%)$ & $40(20.5 \%)$ & $130(100 \%)$ \\
\hline
\end{tabular}


migraine; However regarding the relationship between the migraine in father and infantile colic, the results of our study showed no significant correlation. In a study by Jean and Al-Buhairi in 2001, a family history of migraine was seen in infants who had migraine (19.29 versus 9.29, $P=0.01)$. Infants who had a history of colic crying were more likely to have a family history of migraine than those without a history of colic (18.21 versus $10.37, P=0.0001$ ). These results were consistent with the findings of our study (28). Early childhood periodic syndromes, such as benign attack vertigo syndrome or benign attack torticollis syndrome, can be the primary manifestations of the genes that later cause migraine (20). As new stimuli are present at birth and given their rapid neurodevelopment, the infants' ability to understand these stimuli rapidly increases in the first weeks of life. For example, between birth and two months of life the visual acuity of the infant is more than twice (28). This remarkable increase in ability can explain the increase in colic in the 6-8 weeks of infancy. Further studies are recommended to determine the relationship between the inherited effects of parental genes on the incidence of infantile colic, to confirm this theory.

\section{Conclusion}

The findings of the current study also confirmed that infantile colic was significantly associated with parental diseases therefore parental treatment could also improve infants' condition; infantile colic can be also an early sign of infant disease.

\section{Limitations of the study}

Cross-sectional studies are not assessing the causality, therefore to find precise correlation between infantile colic and migraine, it is suggested to run cohort studies.

\section{Authors' contribution}

EA and AG designed the study, observed accuracy and validity of the study. KD participated in the data collection. MS and KD supervised the project. MS and EA wrote the paper. All authors edited and revised the final manuscript and accepted its publication.

\section{Conflicts of interest}

The authors report no conflicts of interest.

\section{Ethical considerations}

Ethical issues (including plagiarism, data fabrication, double publication) have been completely observed by the authors.

\section{Funding/Support}

The author would like to thank the vice-chancellor of deputy research of Urmia University of Medical Science for financial support (Grant \#3285).

\section{References}

1. Lucassen P, Assendelft W, Van Eijk JTM, Gubbels J, Douwes A, Van Geldrop W. Systematic review of the occurrence of infantile colic in the community. Arch Dis Child. 2001;84:398403. doi: 10.1136/adc.84.5.398
2. Castro-Rodriguez JA, Stern DA, Halonen M, Wright AL, Holberg CJ, Taussig LM, et al. Relation between infantile colic and asthma/atopy: a prospective study in an unselected population. Pediatrics. 2001;108:878-82.

3. Lehtonen LA, Rautava PT. Infantile colic: natural history and treatment. Curr Probl Paediatr. 1996;26:79-85. doi: 10.1016/ s0045-9380(96)80015-6.

4. Thomas D. Of colic and rumbling in the guts. J Paediatr child health. 1995;31:384-6. doi: 10.1111/j.1440-1754.1995. tb00842.x.

5. Balon AJ. Management of infantile colic. Am fam physician. 1997;55(1):235-42.

6. Brazelton TB. Crying in infancy. Pediatrics. 1962;29(4):579-88.

7. Barr RG, Trent RB, Cross J. Age-related incidence curve of hospitalized shaken baby syndrome cases: convergent evidence for crying as a trigger to shaking. Child Abuse Negl. 2006;30:7-16. doi: 10.1016/j.chiabu.2005.06.009.

8. Wessel MA, Cobb JC, Jackson EB, Harris GS, Detwiler AC. Paroxysmal fussing in infancy, sometimes called "colic". Pediatrics. 1954;14:421-35.

9. Lothe L, Lindberg T, Jakobsson I. Cow's milk formula as a cause of infantile colic: a double-blind study. Pediatrics. 1982;70:710.

10. Taubman B. Parental counseling compared with elimination of cow's milk or soy milk protein for the treatment of infant colic syndrome: a randomized trial. Pediatrics. 1988;81:756-61.

11. Iacono G, Carroccio A, Montalto G, Cavataio F, Bragion E, Lorello D, et al. Severe infantile colic and food intolerance: a long-term prospective study. J Pediatr Gastr Nutr. 1991;12:3325. doi: 10.1097/00005176-199104000-00008.

12. Danielsson B, Hwang CP. Treatment of infantile colic with surface active substance (simethicone). Acta Paediatr. 1985;74:446-50.

13. Barr RG, McMullan SJ, Spiess H, Leduc DG, Yaremko J, Barfield $\mathrm{R}$, et al. Carrying as colic "therapy": a randomized controlled trial. Pediatrics. 1991;87:623-30.

14. McKenzie S. Troublesome crying in infants: effect of advice to reduce stimulation. Arch Dis child hood. 1991;66:1416-20. doi: 10.1136/adc.66.12.1416.

15. Fujiwara T, Barr RG, Brant R, Barr M. Infant distress at five weeks of age and caregiver frustration. J Paediatr. 2011;159:425-30. e2.

16. Lee C, Barr RG, Catherine N, Wicks A. Age-related incidence of publicly reported shaken baby syndrome cases: is crying a trigger for shaking? J Dev Behav Paediatr. 2007;28:288-93. doi: 10.1097/DBP.0b013e3180327b55.

17. Talvik I, Alexander RC, Talvik T. Shaken baby syndrome and a baby's cry. Acta Paediatr. 2008;97:782-5.

18. Leung AK, Lemay JF. Infantile colic: a review. J R Soc Prom Health. 2004;124:162-6.

19. Metcalf TJ, Irons TG, Sher LD, Young PC. Simethicone in the treatment of infant colic: a randomized, placebo-controlled, multicenter trial. Pediatrics. 1994;94:29-34.

20. Giffin N, Benton S, Goadsby P. Benign paroxysmal torticollis of infancy: four new cases and linkage to CACNA1A mutation. Dev Med Child Neurol. 2002;44:490-3. doi: 10.1017/ s0012162201002407.

21. Guidetti V, Ottaviano S, Pagliarini M. Childhood headache risk: warning signs and symptoms present during the first six months of life. Cephalalgia. 1984;4:236-42.

22. Bruni O, Fabrizi P, Ottaviano S, Cortesi F, Giannotti F, Guidetti V. Prevalence of sleep disorders in childhood and adolescence with headache: a case-control study. 
Cephalalgia. 1997;17:492-8.

23. Mattsson P. Headache caused by drinking cold water is common and related to active migraine. Cephalalgia. 2001;21:230-5. doi: 10.1046/j.1468-2982.2001.00211.x.

24. Cuomo-Granston A, Drummond PD. Migraine and motion sickness: what is the link? Curr Opin Neurol. 2014;27:105-10.

25. Gelfand AA, Thomas KC, Goadsby PJ. Before the headache: infant colic as an early life expression of migraine. Neurology. 2012;79:1392-6.
26. Tabrizi M, Badeli H, RAD AH, Aminzadeh V, Shokuhifard A. Is infantile Colic an early life expression of childhood migraine? Iran J Child Neurol. 2017;11:37.

27. Ali AS, Elhady MAA. Prevalence and risk factors for infantile colic in Egyptian infants. J Am Sci. 2013;9:340-3.

28. Jan MM, Al-Buhairi AR. Is infantile colic a migrainerelated phenomenon? Clin Paediatr. 2001;40:295-7. doi: 10.1177/000992280104000512. 